\title{
Komposisi Hasil Tangkapan Menggunakan Alat Tangkap Belat di Perairan Kelurahan Tanjung Solok Kabupaten Tanjung Jabung Timur
}

\section{Composition of Catches using Splint Catching Equipment in the Waters of Tanjung Solok Village, Tanjung Jabung Timur Regency}

\author{
Reza Pahrul Rosadi ${ }^{1}$, Lisna ${ }^{1 *}$, Mairizal ${ }^{1}$, Fauzan Ramadhan ${ }^{1}$ \\ ${ }^{1}$ Prodi Pemanfaatan Sumberdaya Perikanan, Fakultas Peternakan, Universitas Jambi \\ Jl. Jambi - Muara Bulian No.KM. 15, Mendalo Darat, Kec. Jambi Luar Kota, \\ Kabupaten Muaro Jambi, Jambi 36361 \\ email: lisna_fapet@unja.ac.id
}

(Received: 15 Januari 2022; Accepted: 01 Maret 2022)

\begin{abstract}
ABSTRAK
Penelitian ini bertujuan untuk mengetahui komposisi hasil tangkapan dengan menggunakan alat tangkap belat di Perairan Kelurahan Tanjung Solok Kabupaten Tanjung Jabung Timur. Penelitian ini telah dilakukan pada bulan Juni - Juli 2021. Metode yang digunakan selama penelitian adalah metode survei, dengan pengamatan langsung ke lapangan dan melakukan wawancara dengan nelayan dan mencatat komposisi ikan yang tertangkap dengan alat tangkap belat. Metode Pengambilan sampel adalah sensus, terhadap 8 orang nelayan yang menggunakan alat tangkap belat. Pengambilan sampel dilakukan setiap hari selama 10 kali penangkapan. Parameter fisik dan kimia perairan yang diukur meliputi suhu, $\mathrm{pH}$, kedalaman, kecepatan arus, salinitas. Hasil tangkapan belat di Perairan Kelurahan Tanjung Solok yaitu ikan gulama, ikan belanak, ikan sembilang, ikan, udang kapur, udang belang, udang agogo, kepiting belang, belut laut, ikan buntal. Komposisi hasil tangkapan alat tangkap belat berjumlah 80,701 ekor dan berat $3.724 \mathrm{~kg}$. Persentasi tertinggi terdapat pada ikan gulama (Johnius trachycephalus) yaitu dengan nilai 45,32 \%, sedangkan persentasi terendah terdapat pada belut (Gymnothorax dorsalis) yaitu $0,04 \%$.
\end{abstract}

Kata Kunci: Alat tangkap belat, Komposisi Hasil Tangkapan, Presentase

\begin{abstract}
This study aims to determine the diversity of catches using splint fishing gear in the waters of Kuala Jambi, Tanjung Jabung Timur Regency. research Thiswas conducted in June - July 2021. The method used during this research was a survey method, with direct observations in the field and conducting interviews with fishermen and recording the composition of fish caught with splints. Sampling method is a census, on 8 fishermen who use splint fishing gear. Sampling was carried out every day for 16 arrests. Physical and chemical parameters of the waters measured included temperature, $\mathrm{pH}$, depth, current velocity, salinity. The splints caught in the waters of Kuala Jambi are gulama fish, mullet fish, nineg fish, fish, lime shrimp, striped shrimp, agogo shrimp, striped crab, sea eel, puffer fish. The catch of the splint fishing gear was 129,627 tails and the weight was $5,899.68 \mathrm{~kg}$. The highest number of yields was gulama fish, which was 59,477 with a total weight of $2,361 \mathrm{Kg}$. The average value of the diversity index is 1.48 , the uniformity index is 0.64 , while the average value of the dominance index is 0.29 . 1 . The diversity of splint catches is in the medium category, while the level of uniformity is included in the high category and the level of dominance is low.
\end{abstract}

Keyword: Splint Fishing Gear, Diversity Catch, Presentage 


\section{Pendahuluan}

Perairan di Kelurahan Tanjung Solok merupakan merupakan perairan estruaria dengan pengaruh masuknya sedimen yang cukup tinggi, sehingga menyebabkan substrat pantai yang berlumpur. Kawasan bersubstrat lumpur adalah kawasan kandungan bahan organik dan memiliki nilai keanekaragaman hayati yang tinggi pula (Putra et al., 2018). Perairan Kelurahan Tajung Solok memiliki karakteristik arus dan gelombang yang tenang, airnya keruh berwarna kecoklatan dengan dasar perairan yang berlumpur dan berpasir. Nelayan disana yang melakukan penangkapan di daerah pinngir pantai, kebanyakan nelayan disana menggunakan alat tangkap belat,jaring insang hanyut, jaring insang tetap,anco,pukat hela dan lain-lain.

Nelayan di perairan Kelurahan Tanjung Solok banyak melakukan penangkapan dengan menggunakan alat tangkap belat oleh karena alat tangkap ini merupakan alat tangkap yang multi spesies atau yang menangkap ikan atau udang dengan berbagai jenis. Hal ini sependapat dengan Rupawan (2010) yang menyatakan alat tangkap belat tergolong alat tangkap yang dapat menangkap ikan dalam jumlah yang banyak, dengan berbagai macam jenis (multi spesies) dan ukuran ikan. Saat dioperasikan dengan cara menghadang dan menjebak ikan yang akan kembali ke sungai utama setelah berupaya secara lateral kepinggiran sungai atau paparan banjiran rawa pasang- surut saat air pasang.

Menurut Bahari et al. (2019) komposisi jenis hasil tangkapan adalah indikasi di dalam perairan yang menjadi daerah penangkapan ikan. Data yang di analisis yaitu komposisi yang meliputi jumlah berat per spesies dan jumlah berat total hasil tangkapan yang di dapatkan saat dilapangan. Komposisi digunakan untuk mengetahui sebarapa besar keragaman hasil tangkapan. Namun sejauh ini belum diketahui komposis hasil tangkapan belat di perairan Kelurahan Tanjung Solok. Oleh karena itu penulis melakukan penelitian tentang "Komposisi Hasil Tangkapan Menggunakan Alat Tangkap Belat di Perairan Kelurahan Tanjung Solok Kabupaten Tanjung Jabung Timur". Tujuan penelitian ini untuk mengetahui komposisi hasil tangkapan dengan menggunakan alat tangkap belat di perairan
Kelurahan Tanjung Solok Kabupaten Tanjung Jabung Timur.

\section{Metode Penelitian}

2.1. Waktu dan Tempat

Penelitian ini dilaksanakan di Perairan Kelurahan Tajung Solok Kabupaten Tanjung Jabung Timur pada tanggal 26 Juni -6 Juli 2021

\subsection{Metode Penelitian}

Metode yang digunakan selama penelitian ini adalah metode survei, dengan pengamatan langsung ke lapangan dan melakukan wawancara dengan nelayan dan mencatat komposisi ikan yang tertangkap dengan alat tangkap belat. Metode Pengambilan sampel adalah sensus, terhadap 8 orang nelayan yang menggunakan alat tangkap belat. Pengambilan sampel dilakukan setiap hari selama 16 kali penangkapan.

\subsection{Prosedur Penelitian}

\subsubsection{Penangkapan}

Sebelum berangkat melaut pertamatama nelayan mempersiapkan alat tangkap belat, kemudian pengoperasian alat tangkap ini dilakukan pada saat air surut, selanjutnya alat tangkap belat yang sedang beroperasi ditunggu selama 5-6 jam, kemudian setelah air dalam keadaan surut barulah hasil tangkapan dapat dipanen. kemudian hitung hasil tangkapan berdasarkan berat $(\mathrm{kg})$ dan jenis ikan (ekor).

\subsubsection{Pengukuran Parameter Lingkungan}

Wadah Pengukuran parameter lingkungan meliputi temperatur (suhu), derajat keasamaan $(\mathrm{pH})$, kedalamaan, kecepatan arus, dan salinitas.

\subsection{Data yang dihimpun}

Metode Data yang dihimpun dalam penelitian ini antara lain, jumlah hasil tangkapan per jenis ikan (ekor), dan berat hasil tangkpan per jenis ikan $(\mathrm{kg})$. Selanjutnya parameter lingkungan yaitu suhu, $\mathrm{pH}$, kedalaman, salinitas dan kecepatan arus.

\subsection{Analisis Data}

$$
\mathrm{P}(\text { Komposisi })=\frac{\mathrm{ni}}{\mathrm{N}} \times 100
$$

Keterangan : 
$\mathrm{P}=$ Komposisi spesies (\%)

ni = Jumlah setiap spesies ikan

$\mathrm{N}=$ Jumlah seluruh hasil tangkapan

\section{Hasil dan Pembahasan}

\subsection{Kondisi Umum Lokasi Penelitian}

Penelitian ini dilaksanakan di perairan Kelurahan Tanjung Solok kabupaten Tanjung Jabung Timur Provinsi Jambi. Perairan Kelurahan Tanjung Solok merupakan perairan estuaria. Perairan estuaria merupakan pertemuan air tawar dengan air asin. Kombinasi pengaruh air laut dan air tawar akan menghasilkan suatu komunitas yang khas, dengan lingkungan yang bervariasi. Perairan estuaria biasanya memiliki produktifitas yang tinggi. Perairan Kelurahan Tanjung Solok biasanya dimanfaatkan masyarakat sekitar sebagai sumber mata pencarian utama ataupun sampingan. Biasanya nelayan melakukan penangkapan ikan di daerah pinggir pantai dan juga didaerah yang agak jauh dari pantai. Salah satu alat tangkap yang digunakan nelayan adalah alat tangkap belat. Alat tangkap ini merupakan alat tangkap yang memiliki hasil tangkapan yang beragam dan juga ramah lingkungan. Nelayan yang menggunakan alat tangkap belat umumnya melakukan penangkapan pada waktu pasang surut. Dikarenakan alat tangkap ini merupakan alat tangkap yang memanfaatkan pasang surut air laut untuk pengoperasiannya.

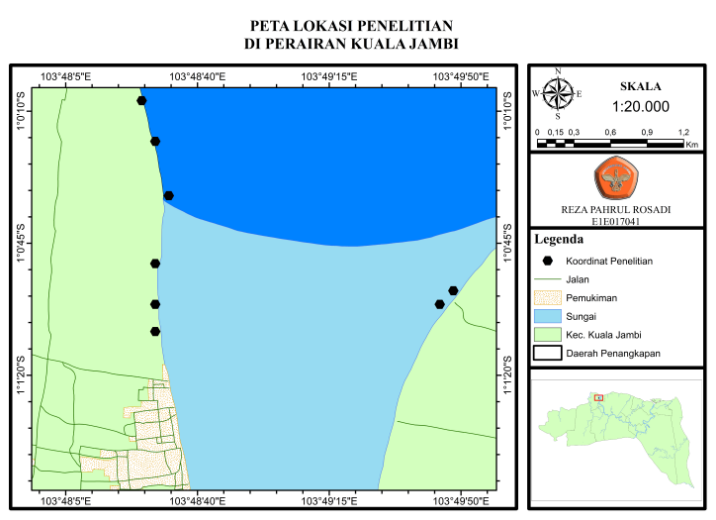

Gambar 1. Peta lokasi penelitian

\subsection{Hasil Tangkapan Alat Tangkap Belat}

Hasil tangkapan belat di perairan Kelurahan Tanjung Solok dapat dilihat pada Tabel 1. yaitu ikan gulama (Johnius trachycephalus), ikan belanak (Mugil cephalus), ikan sembilang (Paraplotosus albilabris), ikan lidah (Cynoglossus lingua), udang Kapur (Metapenaeus brevicornis), udang belang (Parapenaeopsis sculptilis), udang agogo (Penaeus indicus), kepiting belang (Matuta planipes), belut laut (Gymnothorax dorsalis), ikan buntal (Aratutron nigropunchtatus).

Tabel 1. Hasil Tangkapan Belat di perairan Kelurahan Tanjung Solok 10 Hari

\begin{tabular}{llccc}
\hline \multicolumn{1}{c}{ Hasil Tangkapan } & \multicolumn{1}{c}{ Nama Ilmiah } & $\begin{array}{c}\text { Jumlah } \\
(\text { Ekor })\end{array}$ & $\begin{array}{c}\text { Persen } \\
(\mathbf{\%})\end{array}$ & $\begin{array}{c}\text { Berat } \\
(\mathbf{k g})\end{array}$ \\
\hline Hasil Tangkapan Utama & & & & \\
Ikan Gulama & Johnius trachycephalus & 36.578 & 45,32 & 1674 \\
Ikan Belanak & Mugil cephalus & 20.272 & 25,11 & 724 \\
Ikan lidah & Cynoglossus lingua & 7.799 & 9,6 & 709 \\
Ikan sembilang & Paraplotosus albilabris & 1.295 & 1,6 & 198 \\
Udang Kapur & Metapenaeus brevicornis & 7.589 & 9,4 & 186 \\
Udang Belang & Parapenaeopsis sculptilis & 6.053 & 7,5 & 193 \\
Udang Agogo & Penaeus indicus & 988 & 1,2 & 38,6 \\
Hasil Tangkapan Sampingan & & & & \\
\hline Kepiting Belang & Matuta planipes & 48 & 0,06 & 0,58 \\
Hasil Tangkapan Dibuang & & & & \\
\hline Belut & Gymnothorax dorsalis & 33 & 0,04 & 0,47 \\
Ikan Buntal & Aratutron nigropunchtatus & 36 & 0,05 & 0,47 \\
\hline Jumlah & & $\mathbf{8 0 . 7 0 1}$ & & $\mathbf{3 . 7 2 4}$ \\
\hline
\end{tabular}

Berdasarkan Tabel 1 dapat dilihat bahwa hasil tangkapan alat tangkap belat berjumlah 80.701 ekor dan berat $3.724 \mathrm{~kg}$. Jumlah hasil tertinggi adala ikan gulama, yaitu 36.578 dengan berat total $1.674 \mathrm{Kg}$. Ikan gulama Merupakan ikan karnivora, Yang biasa hidup di perairan yang berlumpur. hal ini sesuai dengan pendapat Siagian et al. (2017) yang 
menyatakan Ikan Gulamah termasuk jenis ikan karnivora. Ikan Gulamah merupakan jenis ikan yang hidup di perairan laut dan payau. Pakan alaminya adalah ikan kecil, udang, serasah. Ikan ini menggunakan muaramuara sungai untuk berkembang biak dan memijah atau untuk pengasuhan anak. Ikan Gulama hidup di perairan yang bersuhu rendah, sangat keruh dan berlumpur. Hasil

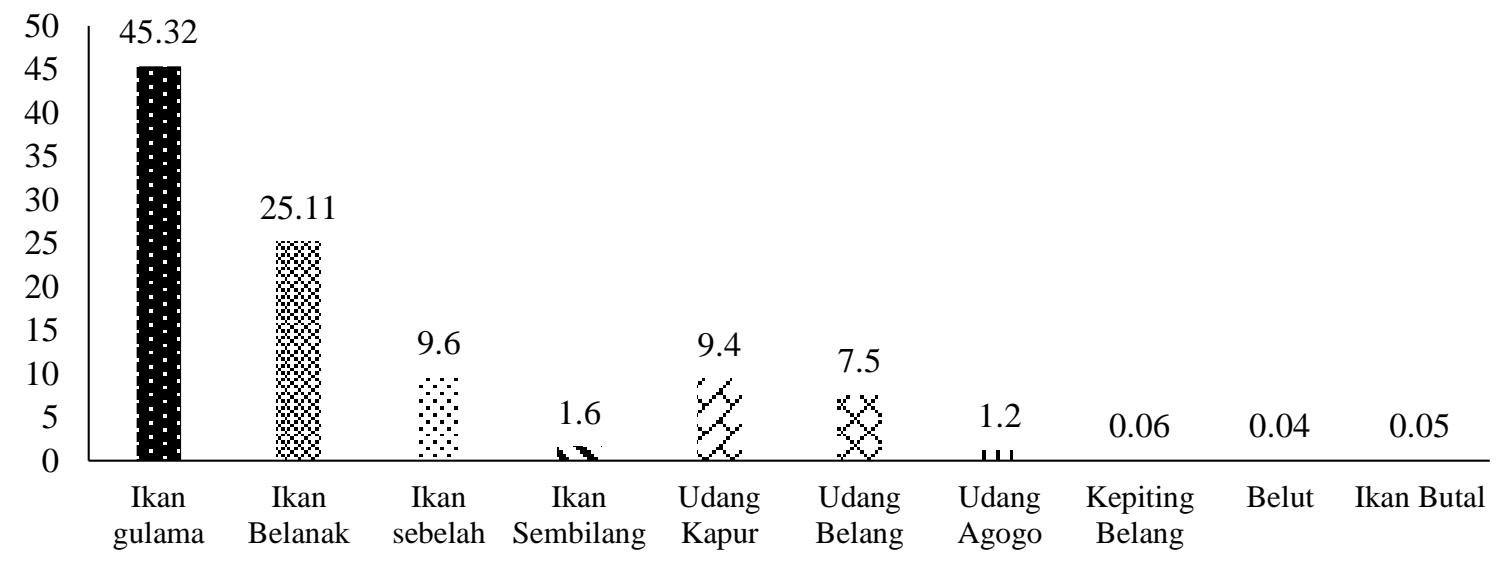

Gambar 2. Komposisi Hasil Tangkapan (\%)

Gambar 2 dapat dilihat bahwa persentasi tertinggi terdapat pada ikan gulama (J.trachycephalus) yaitu dengan nilai 45,32 $\%$. Secara morfologi ikan kepala batu atau yang biasa disebut ikan gulamah merupakan ikan yang habitatnya di perairan pantai hingga ke laut dangkal dan sungai. Ikan ini memiliki bentuk tubuh memanjang dan seluruh bagian tubuhnya tertutup sisik kecuali ujung kepala. Sirip punggung tidak terputus, dengan lekukan yang dalam antara bagian sirip yang berjari-jari keras dengan bagian sirip yang berjari-jari lemah. Ikan ini menjadikan ikanikan kecil dan udang sebagai makanannya (Kottelat et al., 1993). Sedangkan persentasi terendah terdapat pada belut yaitu $0,04 \%$. Hal ini disebabkan habitat dari belut yang biasa hidup di dalam lumpur dengan kedalaman yang mencapai $10 \mathrm{~m}$ dan juga sifat alat tangkap belat yang bersifat menetap di sautu badan perairan (pasif) yang menyebabkan hasil tangkapan belut jarang didapatkan.

\subsection{Hasil Tangkapan Utama (Main Cacth)}

Hasil tangkapan utama (main catch) merupakan komponen dari stok ikan ikan yang utama dicari dari operasi penangkapan ikan, hasil tangkapan utama merupakan sasaran target utama dari alat tangkap yang digunakan atau di operasikan (Earyrs, 2005).
Tangkapan terendah yaitu belut yaitu 33 ekor dan berat total 0,47 . Hal ini disebabkan belut ini memiliki habitat daerah yang dekat dengan daerah pantai. Hal ini sependapat dengan white et al. (2013) yang menyatakan G.dorsalis sering di temukan di daerah yang berlumpur dan dekat dengan daerah pantai, dengan kedalaman $10 \mathrm{~m}$.
Berdasarkan Tabel 1. Hasil tangkapan utama dari alat tangkap belat yang di operasikan di perairan kuala jambi adalah beberapa jenis ikan dan jenis udang. Berdasarkan hasil penelitian terdapat 4 jenis ikan yaitu : ikan gulama, ikan belanak, ikan lidah, ikan sembilang. dan 3 jenis udang yaitu : udang kapur, udang belang, udang. Dari tabel 1 dapat dilihat bahwa hasil tangkapan yang paling banyak di dapatkan adalah ikan gulama yaitu sebesar $2.631 \mathrm{~kg}$ dan hasil tangkapan yang paling sedikit didapatkan adalah udang agogo sebanyak 66,3 kg. Hal ini disebakan ikan gulama merupakan ikan yang hidup diperairan payau. Menurut Kottelat et al. (1993) yang menyatakan Pakan alaminya adalah ikan kecil, udang, serasah. Ikan ini menggunakan muara-muara sungai untuk berkembang biak dan memijah atau untuk pengasuhan anak.

\subsection{Hasil Tangkapan Sampingan (By- Cacth) \\ Hasil tangkapan sampingan sebagai} segala sesuatu yang bukan merupakan sasaran untuk ditangkap nelayan dan dapat terdiri dari penyu, ikan, kepiting, hiu, ikan pari, karang, rumput laut dan sampah dari dasar laut. Hasil tangkapan sampingan juga termasuk hewanhewan dan benda tidak hidup yang 
berinteraksi dengan alat tangkap tetapi tidak sampai ke atas geladak kapal ikan (Eayrs, 2005). Berdasarkan tabel 1. Hasil tangkapan sampingan dari alat tangkap belat yaitu kepiting belang sebanyak $1,08 \mathrm{~kg}$. Menurut Lisna et al. (2021) menyatakan Hasil tangkapan sampingan atau by-catch merupakan istilah yang pada awalnya hanya dikenal di kalangan nelayan. Hasil tangkapan sampingan merupakan bagian dari hasil tangkapan total yang tertangkap secara tidak sengaja bersamaan dengan spesies target diupayakan. Tidak ada satu pun alat tangkap pada usaha perikanan yang tidak menghasilkan hasil tangkapan sampingan

\subsection{Hasil Tangkapan Buangan (Discard)}

Hasil tangkapan yang dibuang adalah bagian dari hasil tangkapan sampingan yang dibuang atau dikembalikan ke laut dalam keadaan hidup atau mati. Termasuk semua hewan dan benda tidak hidup yang tersangkut dengan alat tangkap tetapi tidak sampai di geladak kapal, Hasil tangkapan yang dibuang terdiri dari spesies yang bernilai ekonomi rendah, spesies ikan komersial yang kecilkecil, ikan muda dan sampah dari dasar laut, (Eayrs 2005). Berdasarkan Tabel 1. Hasil tangkapan yang dibuang terdapat 2 spesies yaitu belut, dan ikan buntal. Hasil tangkapan yang paling banyak di dapatkan adalah Ikan buntal sebanyak $0,69 \mathrm{~kg}$ dan yang paling sedikit belut sebanyak $0,67 \mathrm{~kg}$. Discard merupakan hasil tangkapan yang tidak memiliki nilai jual di pasaran. Menurut Hall et al. (2000) menyatakan dengan alasan paling umum untuk membuang hasil tangkapan sampingan adalah spesies bernilai komersial rendah, kondisi hasil tangkapan buruk dan tangkapan kecil (di bawah ukuran minimum ukuran pendaran legal).

\subsection{Parameter Lingkungan}

Parameter lingkungan merupakan salah satu faktor yang mepengaruhi tingkat keberhasilan dalam pengamatan ikan. Hasil pengukuran suhu berkisar antara $28,5^{\circ} \mathrm{C}$. Dari hasil pengamatan maka di dapat suhu yang masih mendukung untuk berjalannya aktivitas organisme diperairan. Hal ini sependapat dengan Gusrina (2007) yang menyatakan bahwa Kisaran suhu air yang sangat diperlukan agar pertumbuhan ikan-ikan pada perairan tropis dapat berlangsung dengan baik berkisar antara $25^{\circ} \mathrm{C}-32^{\circ} \mathrm{C}$. Berikut hasil pengamatan parameter lingkungan selama penelitian dapat dilihat pada Tabel 2

\section{Tabel 2. Rata-Rata Hasil Pengukuran} Parameter Lingkungan

\begin{tabular}{ccc}
\hline $\begin{array}{c}\text { Parameter } \\
\text { Lingkungan }\end{array}$ & Satuan & $\begin{array}{c}\text { Hasil } \\
\text { Pengukuran }\end{array}$ \\
\hline Suhu & ${ }^{\circ} \mathrm{C}$ & $28,5^{\circ} \mathrm{C}$ \\
$\mathrm{pH}$ & - & 7,35 \\
Salinitas & $\mathrm{Ppt}$ & $27,94^{\circ} \% 0$ \\
Kedalaman & Meter & $2,46 \mathrm{~m}$ \\
Kecepatan & Meter/detik & $0,27 \mathrm{~m} / \mathrm{s}$ \\
Arus & & \\
\hline
\end{tabular}

Berdasarkan Tabel 2. Dapat dilihat bahwa pengukuran $\mathrm{pH}$ selama penelitian didapatkan berkisar anatara 7,35. Nilai yang di dapatkan masih tergolong normal untuk organisme perairan. Variasi nilai ini masih dalam batas aman untuk $\mathrm{pH}$ suatu perairan. Umumnya $\mathrm{pH}$ air laut relatif stabil dengan kisaran antara 7,5-8,4. Batasan $\mathrm{pH}$ yang ideal bagi biota laut nilainya berkisar antara 6,5-8,5. Nilai $\mathrm{pH}$ untuk biota laut berkisar antara 78,5. $\mathrm{pH}$ di suatu perairan yang normal berkisar antara 8,0-8,3. Nilai $\mathrm{pH}$ yang baik untuk berbagai kepentingan berkisar antara 6-9 (Souhoka dan Patty, 2013).

Salinitas yang didapatkan selama penelitian berkisar antara $27,94 \%$. Nilai salinitas di perairan kuala jambi masih terbilang optimum dikarena kan masih banyak jenis ikan dan udang yang didapatkan. Menurut Lignot et al. (2000) salinitas mempengaruhi fisiologis kehidupan organisme dalam hubungannya dengan penyesuaian tekanan osmotik antara sitoplasma dan lingkungan. Pengaruh salinitas pada ikan dewasa sangat kecil karena salinitas di laut relatif stabil yaitu berkisar antara $30-$ 36\%.

Pengukuran kedalaman di dapatkan hasil yang berkisar 2,46 m. Kedalaman air mempengaruhi penyebaran dan jenis ikan. Air yang terlalu dangkal menyebabkan perubahan suhu yang besar karena cahaya matahari tembus langsung ke dasar air (Sinaga, 1995). Kedalaman perairan adalah jarak vertical dari permukaan sampai dasar perairan yang biasanya dinyatakan dalam meter (m). kedalaman merumuskan salah satu parameter fisika, dimana semakin dalam perairan maka 
intesitas cahaya yang masuk semakin bekurang (Gonawi, 2009).

Hasil pengamatan yang dilakukan selama penelitian maka didapatkan kecepatan arus yang berkisar $0,27 \mathrm{~m} / \mathrm{s}$. kecepatan arus ini tergolong dalam kecepatan arus sedang. Hal ini sependapat dengan Ihsan (2009) yang menyatakan bahwa kecepatan arus air dapat dibagi menjadi 3 kategori antara lain kecepatan arus yang berkisar antara 0-0,25 $\mathrm{m} / \mathrm{s}$ termasuk ke dalam kategori arus yang lambat kecepatan arus yang berkisar antara $0,26-0,50 \mathrm{~m} / \mathrm{s}$ termasuk kedalam kategori arus yang sedang, kecepatan arus berkisar antar 0,51-1 $\mathrm{m} / \mathrm{s}$ termasuk kedalam kategori arus yang sangat cepat.

Hasil pengamatan pasang surut selama penelitian di perairan Kelurahan Tanjung Solok pasang surut terjadi 1 kali dalam sehari, yang terjadi selama 5-6 jam selama 1 hari. Hal ini sependapat dengan Lisnawati (2015) yang menyatakan pengetahuan mengenai pasang surut dan pola sirkulasi arus pasang surut di perairan pesisir dapat di indikasi tentang pergerakan massa air serta kaitannya sebagai faktor yang dapat mempengaruhi distribusi suatu material di dalam kolom air. Sebernarnya hanya ada tiga tipe dasar pasang surut yang didasarkan pada periode dan keteraturannya, yaitu sebagai berikut: 1 . Pasang-surut tipe harian tunggal (diurnal type) : yakni bila dalam waktu 24 jam terdapat 1 kali pasang dan 1 kali surut, 2. Pasang surut tipe tengah harian/harian ganda (semi diurnal type) : yakni bila dalam waktu 24 jam terdapat 2 kali pasang dan 2 kali surut, 3. Pasang-surut tipe campuran (mixed tides) : yakni bila dalam waktu 24 jam terdapat bentuk campuran yang condong ke tipe harian tunggal atau condong ke tipe harian ganda. Menurut (Surinati, 2007), Pasang surut merupakan suatu fenomena pergerakan naik turunnya permukaan air laut secara berkala yang diakibatkan oleh kombinasi gaya gravitasi dan gaya tarik menarik dari benda-benda astronomi terutama oleh matahari, bumi dan bulan. Pasang surut dan arus yang dibangkitkan pasang surut sangat dominan dalam proses sirkulasi massa air di perairan pesisir.

\section{Kesimpulan dan Saran}

Dari hasil penelitian yang telah dilakukan terhadap komposisi hasil tangkapan alat tangkap belat di perairan Kelurahan Tanjung Solok Kabupaten Tanjung Jabung Timur dapat disimpulkan sebagai berikut : Komposisi hasil tangkapan belat terdiri dari 10 spesies yaitu ikan gulama (Johnius trachycephalus), ikan belanak (Mugil cephalus), ikan sembilang (Paraplotosus albilabris), ikan lidah (Cynoglossus lingua), udang kapur (Metapenaeus brevicornis), udang belang (Parapenaeopsis sculptilis), udang agogo (Penaeus indicus), kepiting belang (Matuta planipes), belut (Gymnothorax dorsalis), ikan buntal (Aratutron nigropunchtatus). Persentasi tertinggi terdapat pada ikan gulama (Johnius trachycephalus) yaitu dengan nilai $45,32 \%$, sedangkan persentasi terendah terdapat pada belut (Gymnothorax dorsalis) yaitu $0,04 \%$.

Berdasarkan penelitian yang telah dilaksanakan, saran peneliti perlunya kesadaran dari semua pihak untuk melestarikan lingkungan agar tetap terjaganya ikan-ikan dan udang di periaran Kelurahan Tanjung Solok.

\section{Daftar Pustaka}

Bahari, D.B., A Nelwan, dan M Zainuddin. (2019). Studi tentang komposisi jenis hasil tangkapan purse seine. Study of catch composition species of purse seine based on fishing ground location In Tanah Beru Coastal Waters, SUB-. Jurnal IPTEKS PSP, 21-43.

Eayrs S. (2005). A Guide to Bycatch Reduction in Tropical Shrimp-Trawl Fisheries. Rome, Italy: Food and Agriculture Organization (FAO) of the United Nations.

Gonawi, G.R. (2009). Habitat dan Struktur Komunikasi Nekton di Sungai Cihideung. Bogor. Jawa Barat. Skripsi. Fakultas Perikanan dan Ilmu Kelautan. Institut Pertanian Bogor.

Gusrina. (2007). Budidaya Ikan. Jilid 1. Direktorat Pembinaan Sekolah Menengah Kejuruan Direktorat Jendral Menejemen Pendidikan Dasar Menengah Departemen Pendidikan Nasional. 160 hlm.

Hall. (1962). Observations on the taxonomy and biology of some Indo-West Pacific Penaeidae (Crustacea, Decapoda). Fish. Publ. (17): 1-229. 
Ihsan, N. (2009). Komposisi Hasil Tangkapan Sondong di Kelurahan Batu Tertip Kecematan Sungai Sembilan Kota Dumai Provinsi Riau. Skripsi. Fakultas Perikanan dan Ilmu Kelautan. Universitas Riau. Pekanbaru.

Kottelat, M., J. Whitten, S.N. Kartikasari dan S. Wirjoadmojo. (1993). Freshwater Fish of Indoneia and Sulawesi. Periplus Edition (HK) Ltd, in Collaboration with Enviromental Management Project. Ministry of State for population and Enviroment. Jakarta: Republic of Indonesia.

Lignot, J.H., C.S. Pierrot dan G. Charmantier. (2000). Osmoregulatory Capacity as a Tool in Monitoring the Physiological Condition and the Effect of Stress in Crustaceans. Aquaculture Journal. 191:209-245.

Lisna et al., (2021). Keanekaragaman Hasil Tangkapan Sondong. (2021). Jurnal Kelautan. (14): 2.

Lisnawati, L.A., B, Rochaddi, dan D.H. Ismunarti. (2015). Studi tipe pasang surut di Pulau Parang Kepulauan Karimun Jawa Kabupaten Jepara Provinsi Jawa Tengah. Jurnal Oseanografi. 2(3): 214-220.

Novasaraseta, N. 2018. Keanekaragaman phytoplankton di Situ Balong Kambang Desa Pasawahan Kecamatan Pasawahan Kabupaten Kuningan. Skripsi. Universitas Kuningan. Kuningan.

Odum, E.P. (1993). Dasar-Dasar Ekologi. Penerbit Gadjah Mada University Press. Terjemah Tjahjono Samingan. Yogyakarta.

Putra, I.K., AT. Maryani, dan H. Syariffudin. (2018). Analisa indeks kepekaan Lingkungan (IKL) Pesisir Pantai Timur Kabupaten Tajung Jambung Timur Provinsi Jambi terhadap potensi tumpahan minyak (oil spill). Jurnal Pembangunan Berkelanjutan. 1(1):2638.
Rupawan. (2010). Kelimpahan dan komposisi hasil tangkapan belat (Beach Barrier Traps) di perairan Estuari Sungai Siak Riau. Prosiding Seminar Nasional Limnologi $V$ Balai Riset Perikanan Perairan Umum.

Sinaga, T.P. (1995). Bioekologi Komunitas Ikan di Sungai Banjaran Kabupaten Banyumas, Jawa Tengah. Tesis. Program Pasca Sarjana. Institut Pertanian Bogor. Bogor. $97 \mathrm{hlm}$.

Siagian, G., H. Wahyuningsih dan T. Barus. (2017). Struktur Populasi Ikan Gulamah (Johnius trachycephalus P.) di Sungai Barumun Kabupaten Labuhan Batu Sumatera Utara. 3(2).

Soegianto, A. (2004). Metode Pendugaan Pencermaran Perairan Dengan Indikator Biologis. Airlangga University Press, Surabaya

Souhoka, J., dan S.I. Patty. (2013). Pemantauan Kondisi Hidrologi dalam Kaitannya dengan Kondisi Terumbu Karang di Perairan Pulau Talise, Sulawesi Utara. Jurnal Ilmiah Platax. 1 (3).

Sriwidodo, D.W.E., A. Budiharjo, dan Sugiyarto. (2013). Keanekaragaman jenis ikan di kawasan inlet dan outlet Waduk Gajah Mungkur Wonogiri. Jurnal Bioteknologi, 10 (2):43-50.

Surinanti, D. (2007). Pasang surut dan energinya. Jurnal Oseana. 32(1) : 1522.

White, W.T., P., R. Last., Dharmadi., R. Faizah. (2013). Habitat Gymnothorax dorsalis. Pusat Penelitian Perikanan Internasional Autralia 